Mini-review

\title{
Targeted abrogation of diverse signal transduction cascades by emodin for the treatment of inflammatory disorders and cancer
}

\author{
Deepti Shrimali ${ }^{a}$, Muthu K. Shanmugam ${ }^{a}$, Alan Prem Kumar ${ }^{a, b, c, d}$, Jingwen Zhang ${ }^{a}$, Benny K.H. Tan ${ }^{a}$, \\ Kwang Seok Ahn ${ }^{\mathrm{e}, *}$, Gautam Sethi ${ }^{\mathrm{a}, \mathrm{b}, *}$ \\ a Department of Pharmacology, Yong Loo Lin School of Medicine, National University of Singapore, Singapore 117597, Singapore \\ ${ }^{\mathrm{b}}$ Cancer Science Institute of Singapore, Centre for Translational Medicine, 14 Medical Drive, \#11-01M, Singapore 117599, Singapore \\ ' School of Biomedical Sciences, Faculty of Health Sciences, Curtin University, Western Australia, Australia \\ ${ }^{\mathrm{d}}$ Department of Biological Sciences, University of North Texas, Denton, TX, USA \\ ${ }^{\text {e } C o l l e g e ~ o f ~ O r i e n t a l ~ M e d i c i n e, ~ K y u n g ~ H e e ~ U n i v e r s i t y, ~ S e o u l ~ 130-701, ~ R e p u b l i c ~ o f ~ K o r e a ~}$
}

\section{A R T I C L E I N F O}

\section{Article history:}

Received 24 June 2013

Received in revised form 9 August 2013

Accepted 12 August 2013

\section{Keywords:}

Emodin

Cancer

Apoptosis

Angiogenesis

Metastasis

\begin{abstract}
A B S T R A C T
Emodin (1,3,8-trihydroxy-6-methylanthraquinone) is a natural occurring anthraquinone derivative isolated from roots and barks of numerous plants, molds, and lichens. It is found as an active ingredient in different Chinese herbs including Rheum palmatum and Polygonam multiflorum, and has diuretic, vasorelaxant, anti-bacterial, anti-viral, anti-ulcerogenic, anti-inflammatory, and anti-cancer effects. The anti-inflammatory effects of emodin have been exhibited in various in vitro as well as in vivo models of inflammation including pancreatitis, arthritis, asthma, atherosclerosis and glomerulonephritis. As an anti-cancer agent, emodin has been shown to suppress the growth of various tumor cell lines including hepatocellular carcinoma, pancreatic, breast, colorectal, leukemia, and lung cancers. Emodin is a pleiotropic molecule capable of interacting with several major molecular targets including $\mathrm{NF}-\kappa \mathrm{B}$, casein kinase II, HER2/neu, HIF-1 $\alpha$, AKT/mTOR, STAT3, CXCR4, topoisomerase II, p53, p21, and androgen receptors which are involved in inflammation and cancer. This review summarizes reported anti-inflammatory and anti-cancer effects of emodin, and re-emphasizes its potential therapeutic role in the treatment of inflammatory diseases and cancer.
\end{abstract}

(c) 2013 Elsevier Ireland Ltd. All rights reserved.
Abbreviations: NF- $\kappa \mathrm{B}$, nuclear factor- $\kappa \mathrm{B}$; I $\kappa \mathrm{B}$, inhibitory subunit of NF- $\mathrm{B}$; IKK, IкB kinase enzyme complex; CK2, casein kinase II; HIF-1 $\alpha$, hypoxia inducible factor 1 alpha; AKT, serine threonine protein kinase B; CXCR, chemokine (C-X-C motif) receptor; ROS, reactive oxygen species; TNF- $\alpha$, tumor necrosis factor; IL, interleukin; iNOS, inducible nitric oxide synthase; ICAM, intracellular adhesion molecule; ELAM, endothelial cell leukocyte adhesion molecule; VCAM-1, vascular cell adhesion molecule 1; VEGF, vascular endothelial growth factor; PI3K, phosphatidylinositol 3-kinase; PKC, protein kinase C; MAPK, mitogen-activated protein kinase; ERK, extracellular signal-regulated kinases; HMGB1, high-mobility group protein B1; TGF, transforming growth factor; LRP1, lipoprotein receptor-related protein 1; EGF, epidermal growth factor; TLR4, toll-like receptor4; COX, cyclooxygenase; HDAC, histone deacetylase; PPAR- $\gamma$, peroxisome proliferator-activated receptor gamma; HSP, heat shock protein; XIAP, X-linked inhibitor of apoptosis; TPA, 12-O-tetradecanoylphorbol-13-acetate; cdk, cyclin-dependent kinase; JAK2, janus kinase 2; STAT3, signal transducer and activator of transcription 3; TRAIL, TNF-related apoptosis-inducing ligand; TRB-3, tribbles homolog 3; FAK, focal adhesion kinase; ERK, extracellular regulated protein; bFGF, basic-fibroblast growth factor; MMP, matrix metalloproteinase; uPA, urokinase plasminogen activator; GRB-2, growth factor receptor-bound protein 2 .

* Corresponding authors. Address: College of Oriental Medicine, Kyung Hee University, Seoul 130-701, Republic of Korea. Tel.: +82 29612316 (K.S. Ahn). Address: Department of Pharmacology, Yong Loo Lin School of Medicine, National University of Singapore, Singapore 117597, Singapore. Tel.: +65 65163267; fax: +65 68737690 (G. Sethi).

E-mail addresses: ksahn@khu.ac.kr (K.S. Ahn), phcgs@nus.edu.sg (G. Sethi).

\section{Introduction}

Most cancers are the result of dysregulation of multiple cell signaling pathways. Therefore, drugs that target multiple cell signaling pathways are needed for prevention and treatment of cancer [1]. Chemotherapy and radiotherapy are the major conventional therapies that have long been used to combat cancer but are ineffective, expensive, and found to impose serious side effects [2]. Multidrug resistance is also emerging as the major problem in the conventional treatment of cancer [3]. Therefore, continuous research has been going onto discover alternative non-toxic drugs and combinational therapies that can replace the existing conventional methods of treatment. Traditional Chinese Medicines (TCM) have attracted great attention not only because of their antiinflammatory and anti-cancer effects but also as they incur low costs, increase the sensitivity of chemo- and radio-therapies and most importantly improve the quality of patient's life and survival. In TCM, constituents of rhubarb (Rheum palmatum) have found a wide range of therapeutic applications including antihyperlipidemic cholesterolemic, antiseptic, antispasmodic, antitumor, aperient, and astringent. Other applications include curing gastric 
and renal disorders, removing bacterial dysentery, promoting blood circulation and improving blood stasis [4].

Major compounds of therapeutic importance in rhubarb are derivatives of anthraquinone, including emodin, rhein, aloe-emodin and physcion [5]. Among these, the most promising natural anthraquinone is emodin because of its chemopreventive and chemotherapeutic potential. Many reports suggest that emodin efficiently suppresses multiple cell signaling pathways and also inhibits cell proliferation, invasion, metastasis, and angiogenesis [2]. Moreover, it has also been used in the treatment of gallstones, inflammation, hepatitis, osteomyelitis, bacterial, and viral infections [6]. This review will focus on various molecular targets modulated by emodin (as shown in Fig. 1) and its promising role in the treatment of inflammatory disorders and cancer.

\section{Reported anti-inflammatory effects of emodin}

Emodin is capable of inhibiting several inflammatory biomarkers that play a crucial role in the development of cancer. Some of these molecules include: Nuclear factor-kappa B (NF- $\kappa B)$, tumor necrosis factor (TNF- $\alpha$ ), interleukin (IL)-1 $\beta$, IL-6, IL-8, chemokine CXCR4, adhesion molecules such as intracellular adhesion molecule 1 (ICAM-1), endothelial leukocyte adhesion molecule (ELAM), vascular cell adhesion molecule 1 (VCAM-1), and angiogenic factors such as vascular endothelial growth factor (VEGF). The potential role of emodin in treating various inflammatory diseases is evident from the fact that it inhibits TNF-induced activation of $\mathrm{NF}-\kappa \mathrm{B}$, which is involved in transcription of various pro-inflammatory genes involved in disease progression. Adhesion molecules such as ICAM-1, VCAM-1 and ELAM-1 contains binding site for $\mathrm{NF}-\kappa \mathrm{B}$. Inhibition of NF- $\kappa \mathrm{B}$ leads to inhibition of monocyte attachment to endothelial cells as well as expression of these adhesion molecules [7]. Emodin has also been shown to suppress lipopolysaccharide-induced pro-inflammatory cytokines (IL-1 $\beta$, IL-6) and chemokines (IL-8, CCL2), and NF- $\kappa$ B activation by disrupting lipid rafts in CD14-negative endothelial cells [8]. Emodin inhibits the differentiation and maturation of dendritic cells (DC), increases $\mathrm{CD} 4^{+} \mathrm{CD} 25^{+}$regulatory $\mathrm{T}$ cells (Tregs), and significantly decreases IL-12p70. It was also shown that emodin inhibits activated $\mathrm{T}$ cell proliferation and decrease cytokine production, IL-2 expression and $\left[\mathrm{Ca}^{2+}\right]$ in cells $[9,10]$. Mechanistic studies revealed that emodin inhibits CXCR4-mediated chemotaxis of leukocytes by inactivating MEK/ERK pathway and thereby proves itself as a potent antiinflammatory agent [11]. Yu et al. [12] showed that treatment of emodin increases the phagocytosis of macrophages, activity of natural killer cells and the expression of cytokines (IL-1 $\beta$ and TNF- $\alpha$ ) in leukocytes isolated from Sprague-Dawley rats. In RAW 264.7 macrophages, treatment with $20 \mu \mathrm{g} / \mathrm{ml}$ of emodin led to inhibition of a panel of inflammation-associated genes such as TNF- $\alpha$, iNOS, IL-10, cytosolic I $\kappa \mathrm{B} \alpha$, IKK- $\alpha$ and IKK- $\gamma$ [13]. High mobility group box 1 (HMGB1) protein is believed to be a potent pro-inflammatory cytokine. Lee et al. [14] first demonstrated that emodin suppresses HMGB1 release, TNF- $\alpha$, and the activation of NF- $\kappa B$ by HMGB1 in human umbilical vein endothelial cells (HUVECs). The anti-inflammatory effects of emodin have drawn the attention of researchers to explore the molecular mechanisms and therapeutic potential of emodin in the treatment and prevention of various inflammatory disorders. Interestingly, the therapeutic potential of emodin has been investigated in various inflammatory diseases such as pancreatitis, asthma, arthritis, atherosclerosis, myocarditis, glomerulonephritis and Alzheimer's disease. These are discussed in brief as follows.

\subsection{Pancreatitis}

Emodin has long been used as a therapeutic agent for treating acute pancreatitis. Acute pancreatitis (AP) is an inflammatory condition characterized by increased paracellular permeability and loss of barrier function in pancreas. Pancreatic claudin and occludin seal the paracellular pathway in epithelium and endothelium and thus play a major role in barrier function. In sodium-taurocholate-induced acute pancreatitic rats, emodin ameliorated pancreatic inflammation and edema, reduced pancreatic TNF- $\alpha$ and IL- 6 levels, decreased paracellular permeability, and promoted claudin-5 and occludin expression [15]. It has been shown that emodin prevents coagulation and improves cryoprotection and microthombosis by inhibiting the release of inflammatory cytokines and abnormal metabolism of eicosanoids [16]. Lou et al. studied the effect and mechanism of emodin on pancreatic repair and remodelling in rats induced with acute pancreatitis by intraperitoneal infusion of caerulein. Emodin not only reduced serum amylase level but also enhanced the expression of TGF- $\beta 1$ gene. Results

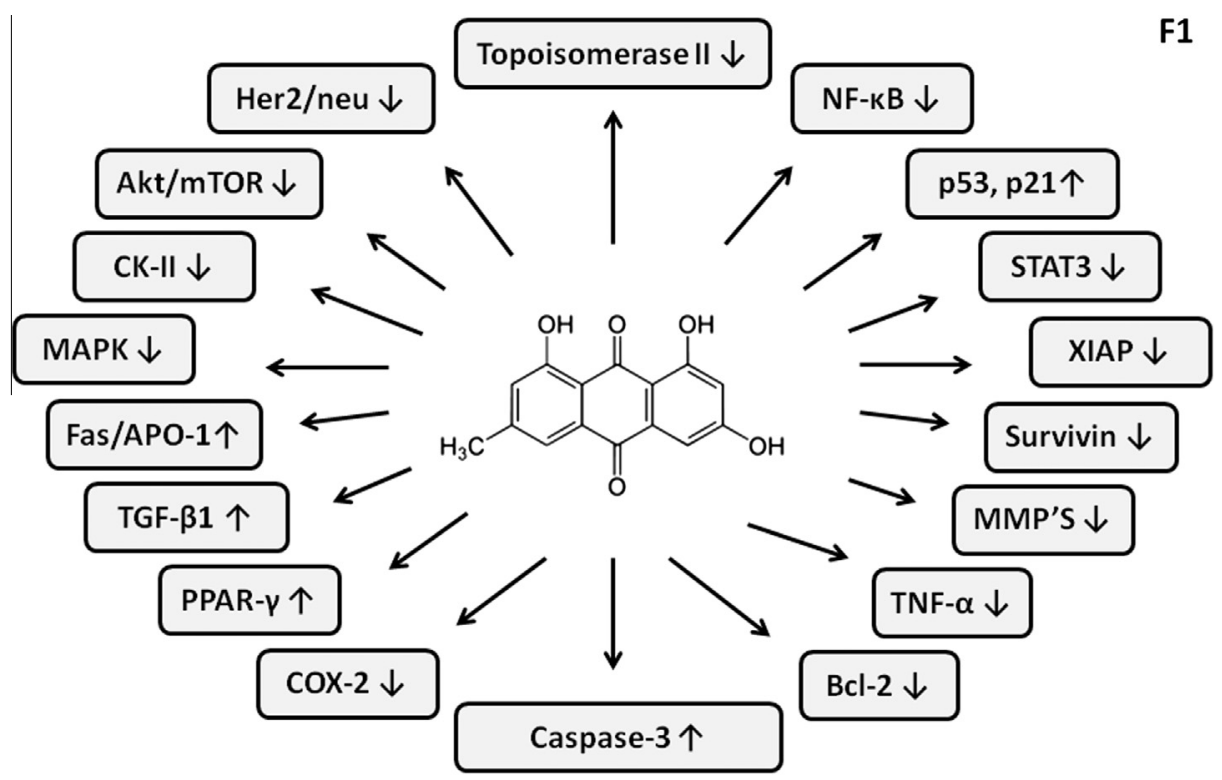

Fig. 1. Key oncogenic targets modulated by emodin in the treatment of inflammatory ailments and cancer. 
suggested that emodin regulates cell growth and differentiation, stimulates the formation of extracellular matrix components, increases DNA synthesis and protein content, and thereby plays an important role in pancreatic repair and remodeling [17]. This was supported by previous studies showing that emodin accelerate pancreatic repair and regeneration by upregulating TGF- $\beta 1$ and EGF gene expressions in AP rats $[18,19]$. Emodin together with baicalin has been found to reduce serum amylase, TNF- $\alpha$ and IL6 levels $[20,21]$. It suppresses expression of toll-like receptor 4 (TLR4) in pancreas and lung and thereby attenuates pancreatic and pulmonary damage in rats with AP [20]. In addition, it reduces pancreatic myeloperoxidase (MPO) activity and stromal cell-derived factor-1 (SDF-1) expression, thereby ameliorates pancreatic inflammation [21]. Li et al. [18] showed that emodin has a protective role in rats with acute necrotizing pancreatitis (ANP) (on intestinal lesions) by suppressing NF- $\kappa B$ pathway, and decreasing TNF$\alpha$ and IL- $1 \beta$ production.

\subsection{Arthritis}

One of the characteristic features of rheumatoid arthritis (RA) is synovial angiogenesis which is supposed to be mediated by various pro-inflammatory cytokines, VEGF, and hypoxia inducible factor-1 alpha (HIF-1 $\alpha$ ). Under hypoxic condition, emodin significantly reduces the production of pro-inflammatory cytokines [TNF- $\alpha$, IL- 6 and IL-8], mediators [prostaglandin E(2) (PGE(2)), matrix metalloproteinase (MMP)-1 and MMP-13] in IL-1 $\beta$ and LPS-treated synoviocytes. Additionally, it decreases vascular endothelial growth factor (VEGF), cyclooxygenase 2 (COX-2), HIF- $1 \alpha$ and histone deacetylase (HDAC1) expression, indicating that it is a novel therapeutic agent in the treatment of arthritis [22]. A recent report by Xiang et al. [23] showed that emodin directly stimulates cellular proliferation and differentiation in MC3T3-E1 osteoblastic cell line and therefore can be used to treat fractures, rheumatoid arthritis, muscle injury and pain.

\subsection{Asthma}

Asthma is a chronic respiratory disease characterized by bronchial inflammation and airway hyperresponsiveness. In the mouse model of asthma, increased production of Th2 cytokines (such as IL-5 and IL-13), eosinophils, and serum levels of immunoglobulin $\mathrm{E}$ (IgE) were observed in mice that were sensitized and challenged with ovalbumin. Moreover, mucin component Muc5ac, and chitinase proteins (Acidic mammalian chitinase (AMCase) and chitinase 3-like protein 4 [Ym2] were also found to be much higher. Pretreatment with emodin, before ovalbumin challenge not only suppressed the characteristics of airway inflammation, mucin components and chitinase proteins expression but also effectively inhibited the NF- $\kappa B$ signaling pathway, which regulates the expression of many inflammatory mediators [24]. Mast cells are important mediators of allergy and anaphylaxis reaction. They express a high-affinity receptor (FceRI) for the Fc region of IgE. Cross linking results in complex sequence of signaling events which leads to degranulation, cytokine/chemokine (TNF- $\alpha$, and IL-6) production and eicosanoid (leukotrienes and prostaglandin) release. In IgE/Ag-stimulated mast cells, Lu et al. demonstrated that emodin inhibits these signaling events in a dose-dependent manner, thus supporting the notion that emodin is a potent anti-allergic agent. Furthermore, emodin was also reported to inhibit FceRI-mediated signaling pathways and multiple downstream signaling processes including $\mathrm{Ca}^{2+}$ mobilization within cells and activation of the mitogen-activated protein kinase (MAPK), phosphatidylinositol 3-kinase (PI3K), and NF- $\kappa B$ pathways. Oral administration of emodin in IgE-sensitized mice lowered the mast cell-dependent passive anaphylactic reaction [25].

\subsection{Atherosclerosis}

Atherosclerosis is a chronic inflammatory, fibroproliferative disease in which formation of plaque occurs inside the blood vessels. Vulnerable artherosclerotic plaques (VAP) are unstable, prone to rupture, leading to thrombosis and sudden cardiac death. They are composed of thin fibrous cap, a large lipid core, and accumulated inflammatory cells [26]. Granulocyte macrophage-colony stimulating factor (GM-CSF), MMP-9, TNF- $\alpha$, and IL-1 $\beta$ are few inflammatory mediators related to atherosclerosis. They promote degradation of extracellular matrix in the plaque and reduce the fibrous cap which consequently leads to disruption of plaque. An important component of plasma lipoprotein is apolipoprotein $\mathrm{E}$ (ApoE) with anti-atherosclerosis function. Zhou et al. conducted experiments to explain the possible mechanism of how emodin stabilizes VAP in the ApoE-deficient mice. Mice were fat-fed for 13 weeks and later administered emodin and simvastin intragastrically. Results showed that emodin significantly reduced the lipid core area and the ratio of lipid to collagen contents, down-regulated the expression of the above-mentioned inflammatory mediators and promoted PPAR- $\gamma$ expression and thus played a beneficial role in stabilizing VAP [27]. In rat aortic smooth muscle cells (RASMCs), emodin attenuates TNF- $\alpha$ induced proliferation, migration, MMP-2 and MMP-9 expression and NF- $\kappa$ B activation [28]. Reports have shown that emodin exerts its anti-atherogenic effects in TNF$\alpha$ induced human aortic smooth-muscle cell (HASMC) proliferation via caspase-and mitochondria-dependent apoptotic pathways $[29,30]$. Heo et al. showed that treatment of human monocyte, THP-1, with emodin followed by treatment with light significantly reduced the production of ROS as well as ICAM-1, IL-8, MCP-1, TNF- $\alpha$, and IL-6. Emodin also reduced the phosphorylation of the p38 MAPK and I $\kappa \mathrm{B} \alpha$. Furthermore, it inhibited the NADPH oxidase p47 (phox), small interference RNA (siRNA) and NF- $\kappa B$ activation [30]. The sonodynamic effect of emodin on THP-1 derived macrophages was shown by Gao et al. [31] macrophages exposed to ultrasound showed typical features of apoptosis such as chromatin fragmentation and disturbed cytoskeletal filaments.

\subsection{Myocarditis}

Myocarditis is inflammation of the heart muscle in which high expression of pro-inflammatory chemokines and cytokines have been observed. In rat model of experimental autoimmune myocarditis (EAM), $50 \mathrm{mg} / \mathrm{kg} /$ day emodin was administered to 3-6 weeks old male Lewis rat. Echocardiographic and histopathological examination revealed that treatment with emodin considerably enhanced the functioning of the left ventricle and reduced the severity of myocarditis. Moreover, serum levels of pro-inflammatory cytokines, TNF- $\alpha$ and IL- $1 \beta$, were also significantly reduced by emodin treatment. Nuclear factor- $\kappa B p 65$ (NF- $\kappa B p 65$ ), a regulator of pro-inflammatory cytokines, was also suppressed by emodin treatment [32]. Wu et al. showed that emodin reduced myocardial infarct size (MIS) in murine model of acute myocardial infarction (AMI). Moreover, emodin significantly protected against myocardial cell injury as evidenced by the fact that it inhibited inflammation by suppressing TNF- $\alpha$ and NF- $\kappa$ B as well as caspase-3mediated apoptosis [33].

\subsection{Glomerulonephritis}

Glomerulonephritis (GN) is inflammation of glomeruli characterized by accumulation of extracellular matrix. It has been shown that inhibition of protein kinase CK2 can be effective in the treatment of glomerulonephritis [34]. According to the study conducted by Wei et al. in GN induced rats, emodin decreased the expansion of mesangial matrix. It also inhibited production of fibronectin 
which is an important component of mesangial extracellular matrix. Decreased IL-1 $\beta$ level suggests the therapeutic role of emodin in mesangioproliferative glomerulonephritis [35]. Liu et al. studied the effects of emodin on human fibroblasts in culture of kidneys in patients with lupus nephritis (LN). Emodin inhibited the proliferation of fibroblasts. Furthermore, it was also found to promote apoptosis by upregulating the expression of c-myc gene [36].

\subsection{Alzheimer's disease}

Deposition of $\beta$-amyloid protein $(A \beta)$ and accumulation of tau protein into paired helical filaments (PHFs) is a hallmark of Alzheimer's disease. Pickhardt el al. [37] found that emodin was effective in inhibiting the abnormal aggregation of tau protein into PHFs. Emodin proved to be an efficient neuroprotective drug as it up-regulated Bcl-2, activated ER/PI3K/AKT pathways and inhibited JNK1/ 2 phosphorylation and thereby protected cortical neurons from A 325 -35-induced toxicity [38]. The potential effects of emodin on major pro-inflammatory diseases are summarized in Table 1.

\section{Reported anti-cancer effects of emodin}

The anti-cancer effects of emodin have been studied in different tumor cell lines and in pre-clinical animal models. Some of these are discussed in brief below:

\subsection{Anti-proliferative effects of emodin}

Anti-proliferative activity of emodin has been substantiated in a wide variety of tumor cell lines including breast cancer (Her-2/ neu) [39], gastric carcinoma (SGC-7901) [40], pancreatic cancer (SW1990) [41], adenocarcinoma (Anip973) [42], prostate cancer (LNCap) [43], hepatocellular carcinoma (HepG2, Huh7, Нер3B, SMMC-7221) [44,45], leukemia (K562, jurkat, HEL), glioma (C6) [46] and lung cancer (NIH-H460, NSCLC) [47]. Protein tyrosine kinase catalyzes the phosphorylation of tyrosine residues in many protein substrates such as MAPK, PKC, NF- $\kappa B$, ERK and thereby plays an important role in regulating cellular proliferation [48]. Emodin efficiently suppresses these signaling cascades and thereby exerts anti-proliferative effects. Emodin suppresses HER-2/neu tyrosine kinase activity in HER-2/neu-overexpressing breast cancer cells MDA-MB-435 and thereby represses proliferation of these cells [49]. Emodin sensitized HER-2/neu-overexpressing lung cancer cells to chemotherapeutic drugs [50]. Emodin was found to repress transformation and metastasis-associated properties of HER2/neu-overexpressing breast cancer cells [51]. Emodin was shown to inhibit tyrosine-kinase-mediated phosphorylation of vascular endothelial growth factor (VEGF) receptors in colorectal cancer cells [52]. Emodin induced DNA damage by reactive oxygen species (ROS) generation, thereby inhibiting cellular proliferation. Mammalian recombination protein Rad51 and excision repair cross complementary-1 (ERCC-1) play an important role in repairing damaged DNA. It has been seen that the expression of both these proteins are high in cancer, causing instability of the genome. Treatment of emodin increases the antitumor antibiotic, mitomycin C (MMC)-induced cytotoxicity via ERK1/2 inactivation and Rad51 down-regulation in lung cancer H1703 or A549 cells [53] and has an additive effect on cisplatin-induced cytotoxicity via downregulating ERCC1 expression in human NSCLC cells through regulation of the ERK1/2 signaling pathway [54]. In human nonsmall cell lung cancer (NSCLC), emodin with (or without) capecitabine induced cytotoxicity by down-regulating the expression of Rad51 and ERCC1 [47,55].

In another study, Yang et al. [56] showed that emodin exhibited cytotoxicity on esophagus cancer EC/CUHK1 cell line by significantly increasing ROS production both in vitro and in vivo. Emodin could reverse the multi-drug resistance in breast cancer MCF-7/Adr cells and down-regulate ERCC1 protein expression [57]. Similarly, in prostate cancer, co-treatment with emodin and cisplatin significantly increased the production of ROS and chemosensitivity in DU-145 cell line. The same study also reported that emodin down-regulates multi drug resistance (MDR1) gene and suppressed HIF-1 $\alpha$ expression both in vitro and in vivo [58]. Li et al. showed that in drug-resistant ovarian tumor A2780/taxol cells, emodin could suppress the Pgp drug-pump, which is responsible for development of drug resistance in cancer cells as well as MDR1 gene expression. Moreover, expression of anti-apoptotic molecules such as XIAP and survivin were also significantly down-regulated [59]. Interestingly several reports also suggest that emodin has been used as an effective agent to target the down-regulation of androgen receptor (AR) for treatment and prevention of advanced prostate cancer. In this respect, emodin has been shown to directly target AR to suppress prostate cancer cell growth in vitro. Emodin treatment resulted in repressing

Table 1

Reported anti-inflammatory effects of emodin.

\begin{tabular}{|c|c|c|}
\hline Diseases & Mechanism(s) of action & Refs. \\
\hline \multirow[t]{5}{*}{ Pancreatitis } & Reduces pancreatic TNF- $\alpha$ and IL-6 levels; ameliorates pancreatic inflammation and edema & [15] \\
\hline & $\begin{array}{l}\text { Inhibits inflammatory cytokines and abnormal metabolism of eicosanoids; prevents coagulation, improves cryoprotection } \\
\text { and microthombosis }\end{array}$ & {$[16]$} \\
\hline & Reduces serum amylase level; increases TGF- $\beta 1$ gene expression in AP-induced rats & [17] \\
\hline & Reduces pancreatic MPO activity and SDF-1 expression; ameliorates pancreatic inflammation & [21] \\
\hline & Suppresses NF- $\kappa B$ pathway, and decreases TNF- $\alpha$ and IL- $1 \beta$ in ANP rats. & {$[18]$} \\
\hline Arthiritis & $\begin{array}{l}\text { Reduces TNF- } \alpha \text {, IL-6 and IL-8, PGE (2), MMP-1 and MMP-13 and VEGF, COX-2, HIF- } 1 \alpha \text { and HDAC-1 expression in IL- } 1 \beta \text { and } \\
\text { LPS-treated synoviocytes }\end{array}$ & {$[22]$} \\
\hline \multirow[t]{2}{*}{ Asthma } & $\begin{array}{l}\text { In the mouse model of asthma, increases amounts of Th2 cytokines, eosinophils, and serum levels of IgE. Increases mucin } \\
\text { components and chitinase protein levels, inhibits NF- } \mathrm{B} \text { pathway }\end{array}$ & {$[24]$} \\
\hline & $\begin{array}{l}\text { Inhibits degranulation, generation of eicosanoids (prostaglandin and leukotriene), and secretion of cytokines (TNF- } \alpha \text { and } \\
\text { IL-6) in IgE/Ag-stimulated mast cells. }\end{array}$ & [25] \\
\hline \multirow[t]{3}{*}{ Atherosclerosis } & Downregulates GM-CSF, MMP-9, TNF- $\alpha$, and IL-1 and promotes PPAR- $\gamma$ expression; stabilize the VAP & [27] \\
\hline & Attenuates TNF- $\alpha$-induced proliferation and migration, MMP-2 and MMP-9 expression and NF- $\kappa$ B activation & {$[28]$} \\
\hline & Decreases ICAM-1, IL-8, MCP-1, TNF- $\alpha$, and IL-6 and phosphorylation of the p38 MAPK and IкB- $\alpha$ in human monocytes & {$[30]$} \\
\hline \multirow[t]{2}{*}{ Myocarditis } & Reduces serum levels of pro-inflammatory cytokines, TNF- $\alpha$ and IL-1 $\beta$ and NF- $\kappa B$ (p65) & [32] \\
\hline & Suppresses TNF- $\alpha$ expression and NF- $\kappa$ B activation; reduces myocardial infarct size, protects against myocardial cell injury & [33] \\
\hline Glomerulonephritis & Decreases IL-1level; inhibits fibronectin production & [35] \\
\hline Alzheimer's disease & $\begin{array}{l}\text { Up-regulates Bcl-2; activates ER/PI3K/AKT pathway and inhibits JNK1/2 phosphorylation; Protects cortical neurons from } \\
\text { A } 325 \text {-35-induced toxicity }\end{array}$ & [38] \\
\hline
\end{tabular}


androgen-dependent transactivation of AR by inhibiting AR nuclear translocation. Furthermore, emodin decreased the association of $\mathrm{AR}$ and heat shock protein 90 and increased the association of AR and MDM2, which in turn induced AR degradation through proteasome-mediated pathway in a ligand-independent manner [60]. Emodin down-regulated AR in LNCaP under normoxic and hypoxia-like conditions (simulated by $\mathrm{CoCl}_{2}$ and low-density lipoprotein receptor-related protein 1 (LRP1) under normoxia [61]. Similarly, $\mathrm{Yu}$ et al. [43] showed that in LNCaP cells emodin reduces the expression and function of AR and enhances the expression of p53 and p21.

\subsection{Effect on pro-inflammatory transcription factor $N F-\kappa B$}

$\mathrm{NF}-\kappa \mathrm{B}$ is a pro-inflammatory transcription factor that controls transcription of genes involved in cell proliferation and cell survival. Constitutive expression of $\mathrm{NF}-\kappa \mathrm{B}$ is an emerging hallmark of cancer. In fact, constitutive NF- $\kappa \mathrm{B}$ activation is generally associated with cancer proliferation, survival, chemoresistance, radioresistance, and progression of various cancers. Thus, NF- $\kappa \mathrm{B}$ emerges as an important target for developing adjuvant cancer treatment. Liu et al. [41] showed that emodin promotes apoptosis and exhibits anti-metastatic effect on SW-1990 pancreatic cancer cells both in vitro and in vivo by suppressing NF- $\kappa$ B DNA binding activity, survivin and MMP-9 proteins. Treatment of emodin with 12-0-tetradecanoylphorbol-13-acetate (TPA) -stimulated cancer cells significantly reduces $I \kappa B \alpha$ degradation, translocation of p65 to nucleus and thereby inhibits NF- $\kappa B$ signaling pathway in human cancer HSC5 and MDA-MB-231 cell line [62].

\subsection{Reported effects on apoptosis}

Apoptosis is generally triggered by two major pathways. One pathway is the death receptor-induced extrinsic pathway which includes ligands and their receptors such as FAS, TNF, TRAIL, caspases and $\mathrm{Bcl}$. The other pathway is the mitochondria-apoptosome-mediated apoptotic intrinsic pathway which includes key effector caspases-8, -9 and -10 . Emodin is characterized as a strong apoptotic agent. Several reports indicate that emodin induces apoptosis by ROS production, caspase- and mitochondrial dependent signaling pathways in various cancer cell lines, including human tongue squamous cancer SCC-4 cells [63], apoptosis human breast cancer BCap-37 cells [64], human lung adenocarcinoma A549 cells [65], human cervical cancer cells [66] and human colon cancer cells (LS1034) [67]. Emodin could inhibit the growth of HepG2 cells significantly as evident by $\mathrm{IC}_{50}$ of $36+/-2.6 \mu \mathrm{g} / \mathrm{ml}$ [44]. Emodin arrests liver cancer Huh7, Hep3B, and HepG2 cells in $\mathrm{G} 2 / \mathrm{M}$ phase, which is accompanied by increase in expression levels of cyclin A, cyclin B, Chk2, Cdk2, and p27 and decrease in expression levels of Cdc25c and p21 [45]. It is evident that emodin induces apoptosis via p53-dependent pathway. p53 is a tumor suppressor gene, which is involved in inhibition of cellular proliferation by inducing cell cycle arrest and apoptosis. It was demonstrated by the use of p53 inhibitor (such as pifithrin-alpha) or knocking down the expression of p53 that emodin induces ATM phosphorylation at Ser1981 resulting in phosphorylation of p53Ser15 which simultaneously resulted in activation of Bax, release of cytochrome $C$ followed by apoptosis in human lung adenocarcinoma A549 cells [68]. Study on hepatocarcinoma cells Huh7, Hep3B, and HepG2 revealed that treatment of emodin retards NF- $\kappa \mathrm{B} / \mathrm{p} 65$ protein level, and $\mathrm{Bcl}-2$ expression, with simultaneous increase in p53 levels. It releases mitochondrial cytochrome C and also activates caspase-8 and -9 [69].

Similarly, in another study, Shieh et al. [70] showed that in HepG2/C3A cells overexpression of p53 and p21 is responsible for induction of apoptosis. Also, it was observed that levels of
Fas/APO-1 and caspase-3 were changed by emodin. Reports showed that treatment with emodin caused cell cycle arrest. Emodin caused G2/M arrest in liver cancer cells and human colon carcinoma HCT116 cells [45,52], blocked the $G(0) / G(1)$ phase in myeloid leukemia cell line and Anip973 [42,71], G1 to S phase of the cell cycle in human colon carcinoma HCT-15 cells [72] and breast cancer MDA-MB-453 cells [73].

Emodin has also been shown to induce apoptosis by decreasing c-myc, hTERT, Bcl-2, procaspase-3, -8 and -9 expression and increasing caspase- 3 and poly ADP ribose polymerase (PARP) expressions in leukemic Jurkat cells [74]. Muto et al. [6] showed that emodin induced apoptosis by selectively inhibiting interleukin-6-induced JAK2/STAT3 pathway and down-regulating myeloid cell leukemia 1 [Mcl-1]. Our recent findings also suggest that emodin can suppress STAT3 activation in a dose- and time-dependent manner in hepatocellular carcinoma cells through the induction of tyrosine phosphatase SHP-1 [75].

Emodin induced apoptosis by down-regulating c-myc expression in HL-60 cells, p21 expression in myeloid leukemia cell line $\mathrm{K} 562$, and XIAP, survivin and beta-catenin in pancreatic cancer cells [76-78]. The study by Lee et al. $[79,80]$ demonstrated that emodin induces apoptosis in human lung squamous cell carcinoma $\mathrm{CH} 27$ cell death by Bax death pathway and Fas pathway. Inhibition of CK2 by emodin increased apoptotic cell death mediated by Fas ligand (FasL)/Fas, tumor necrosis factor (TNF)/TNF receptor and TNF-related apoptosis-inducing ligand (TRAIL)/TRAIL receptor in HepG2, Hep3B and HeLa cells [81]. Our group recently investigated the potential of emodin to enhance apoptosis induced by TRAIL in hepatocellular carcinoma (HCC) cells. As observed by MTT cytotoxicity assay and the externalization of the membrane phospholipid phosphatidylserine, we found that emodin can significantly potentiate TRAIL-induced apoptosis in HCC cells. When investigated for the mechanism(s), we observed that emodin can downregulate the expression of various cell survival proteins, and induce the cell surface expression of both TRAIL receptors, death receptors (DR) 4 as well as 5. In addition, emodin increased the expression of C/EBP homologous protein (CHOP) in a time-dependent manner. Knockdown of CHOP by siRNA decreased the induction of emodin-induced DR5 expression and apoptosis. Emodin-induced induction of DR5 was mediated through the generation of ROS, as N-acetylcysteine blocked the induction of DR5 and the induction of apoptosis. Also, the knockdown of X-linked inhibitor of apoptosis protein by siRNA significantly reduced the sensitization effect of emodin on TRAIL-induced apoptosis. Overall, our findings clearly indicate that emodin can indeed potentiate TRAIL-induced apoptosis through the downregulation of anti-apoptotic proteins, increased expression of apoptotic proteins, and ROS mediated upregulation of DRs in HCC cells [82].

Similarly, Jing et al. [83] found that emodin can generate ROS, which induced a reduction of the intracellular mitochondrial transmembrane potential (DeltaPsim), followed by the activation of caspase- 9 and caspase-3, leading to DNA fragmentation and apoptosis in HepG 2 cells. In esophagus carcinoma EC-109 cells, emodin decreased intracellular $\mathrm{pH}(\mathrm{pHi})$ significantly by $0.47-0.78$ units and generated ROS, leading to cellular apoptosis [84]. Tribbles homolog 3 (TRB-3) is a pro-apoptotic gene and it has been shown that inhibition of TRB3 by siRNA knockdown attenuated emodininduced microglial cytotoxicity [85]. Emodin potentiated arsenicinduced apoptosis in HeLa cells by inducing production of ROS that in turn causes mitochondrial transmembrane potential to collapse and subsequently inhibit NF- $\kappa \mathrm{B}$ activation, both in vitro and in vivo [86]. Similarly, an emodin azide methyl anthraquinone derivative (AMAD) induced apoptosis via mitochondrial pathway involving caspase-8 activation in both human breast cancer cell line MDAMB-453 and human lung adenocarcinoma Calu-3 cells [85]. Liu et al. [87] reported that emodin induced apoptosis in human 
pancreatic cancer cell line Panc- 1 by declining the mitochondrial membrane potential (MMP) in a dose- and time-dependent manner.

\subsection{Effect of emodin on the PI3K/AKT/mTOR pathway and other oncogenic molecular targets}

Improper regulation of PI3K/AKT pathways has been reported in many human cancers [88]. Zheng et al. [71] found that emodin significantly down-regulated expression of AKT, p-AKT, ІкB- $\alpha$, p-ІкB$\alpha, \mathrm{p} 65, \mathrm{p}-\mathrm{p} 65, \mathrm{mTOR}$ and p-mTOR in AKT signaling pathway, thereby promoting apoptosis in HL-60 cells. It has been illustrated in many cancer cells that emodin down-regulated phosphoinositide 3-kinase (PI3K)/AKT pathway and thereby induced apoptosis [89-91]. Similarly, Yan et al. showed that in Her2/neu-overexpressing cancer cells, treatment with emodin inhibited MAPK and PI3K/AKT-dependent pathway and thus inhibited cell growth and induced apoptosis. It was shown for the first time that emodin treatment led to blockade of Her2/neu binding to Hsp90, intracellular redistribution, enhanced ubiquitinylation and thus proteasomal degradation of Her2/neu, which may represent a novel approach for the targeted therapy of Her2/neu-overexpressing cancers [92]. Kim et al. reported the anti-invasive effects of emodin as evidenced by the fact that it efficiently suppressed hyaluronic acid (HA)-induced MMP secretion of glioma by inhibiting phosphorylation of focal adhesion kinase (FAK), extracellular regulated protein kinase (ERK1/2) and AKT/PKB activation. It also inhibited AP-1 and $\mathrm{NF}-\kappa \mathrm{B}$ expression both in vitro and in vivo [46].

Topoisomerase II is an enzyme involved in many cellular processes such as DNA replication, recombination and transcription [93]. A number of reports have suggested that genotoxicity of emodin may be mediated by Topo II [94-96]. Li et al. studied the molecular mechanism by which emodin facilitated its inhibition of Topo II. Emodin stabilized Topo II-DNA cleavage complexes and inhibited ATP hydrolysis of Topo II. Both the events led to induction of double stranded breaks in DNA and thereby damaged DNA [97]. The cytochrome P450-dependent mono-oxygenase system is involved in the metabolism of a wide variety of xenobiotics, such as drugs, carcinogens, and many other toxic chemicals. Wang et al. [98] studies showed that emodin is an inducer of P450s 1A1 and 1B1 protein and mRNA in human lung adenocarcinoma CL5 cells. In human NIH-H460 lung cancer cells and SMMC-7721 liver cancer cells emodin induced apoptosis and inhibited retinoid $\mathrm{X}$ receptor transcriptional activity in a dose-dependent manner [99]. Radha et al. [100] was the first to show that emodin effectively enhances the fibrinolysis and wound healing by up-regulating urokinase plasminogen activator (uPA) system and plasminogen activator inhibitor (PAI-1) expressions in human fibroblast cells. Overall, these findings clearly establish the enormous potential of emodin to target multiple signal transduction cascades in diverse tumor cell lines.

\subsection{Anti-angiogenic and anti-metastatic effects of emodin}

Angiogenesis is a crutial step in tumor progression. This step is controlled by various angiogenic factors such as TGF- $\alpha$, VEGF, fibroblast growth factor. Kwak et al. demonstrated that emodin inhibited VEGF-A-induced proliferation, migration, invasion and tube formation of HUVECs in vitro. Moreover, emodin also blocks basic fibroblast growth factor-induced proliferation and migration of HUVECs and VEGF-A-induced tube formation of human dermal microvascular endothelial cells. Emodin arrested growth of VEGFA-stimulated HUVECs at the G0/G1 phase of cell cycle through down-regulation of cyclin D1 and E. KDR/Flk-1 plays an important role in proliferation, migration and differentiation of endothelial cells in response to VEGF-A. Emodin blocked VEGF-A-induced tyro- sine phosphorylation of KDR/Flk-1 and downstream signaling molecules including FAK, ERK1/2, p38 MAPK, AKT, and endothelial nitric oxide synthase, thereby showing its potential anti-angiogenic effects [101]. In another experiment, emodin was shown to inhibit the proliferation of primary cultured bovine aortic endothelial cells in the absence or presence of basic-fibroblast growth factor (bFGF) or the presence of vascular endothelial growth factor (VEGF) in a dose-dependent manner. Additionally, emodin could also cause cell cycle arrest at G2/M phase and down-regulated cyclin B1, P34cdc2, and Bcl-2 protein expression while keeping Bax protein expression unaffected [102]. Overexpression of p53 reduced VEGF production. Emodin induced p53-dependent apoptosis. Its effects on constitutive photomorphogenesis signalosomeassociated kinases and (CSN)-associated kinases and also on cjun suggest that it might reduce VEGF production in tumor cells, thus showing its potential anti-angiogenic effects [103].

Inhibition of MMPs has been explored as a therapeutic goal for almost two decades as they are involved in degradation of extracellular matrix and control tumor invasion and metastasis (41). Lin et al. [104] for the first time demonstrated that emodin suppressed tumor angiogenesis in vitro and in implanted pancreatic cancer tissues by inhibiting the expression of angiogenesis-associated factors such as NF- $\mathrm{BB}$ and its regulated factors VEGF, MMP-2, MMP-9, and eNOS. Recent studies probing the anti-angiogenic potential of emodin revealed that emodin suppressed phosphorylation of extracellular signal-regulated kinase ERK $1 / 2$ and expression of matrix metalloproteinase-9 (MMP-9) [105]. Emodin also suppressed the NO-mediated up-regulation of MMP2 and MMP9 in the colon cancer cell line, WiDr. By reducing ECM degradation, these proteins promote tumor angiogenesis and metastasis [106]. It has been shown that emodin inhibited the invasiveness of human cancer cells by suppressing MMP9 expression and inhibiting AP-1 and NF-KB signaling pathways. Similarly, Lee et al. [107] also showed that emodin suppresses TNF- $\alpha$ induced MMP-1 expression through the inhibition of the AP-1 signaling pathway.

In addition to MMPs, CXCR4 and CXCR12 are found to be involved in inhibition of tumor cell proliferation, invasion, and metastasis [108]. It was shown by Ok et al. for the first time that emodin can down-regulate CXCR4 and HER2 expression in both prostate DU145 and lung A549 tumor cells and this could be mediated by suppression of p65 nuclear translocation. A similar study showed that emodin can significantly inhibit CXCL12-induced cellular migration and invasion of the tumor cells [109]. Lu et al. suggested that emodin inhibited migration and invasion of SH-SY5Y cells by selectively targeting the NF- $\kappa$ B pathway that leads to the down-regulation of MMP2, MMP7 and MMP9 pathways in vitro. Furthermore, emodin inhibited the metastasis and angiogenesis signaling proteins GRB2, RhoA, HIF-1 $\alpha$, VEGF, FAK, iNOS, COX2, p-p38, p-c-jun levels, but promoted the levels of PKC, PI3K, and NF- $\kappa B$ p65 [110]. Emodin has been reported to inhibit phosphatase of regenerating liver-3 (PRL-3), and cell proliferation in SGC-7901 human gastric carcinoma cell line. In another study DLD-1 (PRL3) colon tumor cells, emodin has been shown to inhibit cell migration and invasion $[40,111]$. The in vitro anti-cancer effects of emodin in various cancer cell lines are summarized in Table 2.

\section{In vivo anti-cancer effects of emodin}

A number of studies have also been performed to investigate the potential in vivo anticancer effects of emodin in diverse tumor models. Singh et al., (2011) have reported that treatment of emodin induced apoptosis of Dalton's lymphoma (DL) in vivo as shown by a decrease in the number of viable cells, and in $\mathrm{Bcl} 2 / \mathrm{Bax}$ ratio, and subsequent release of mitochondrial cytochrome c. Moreover, it was found that the $\mathrm{Cu}-\mathrm{Zn}$-superoxide dismutases (SOD1) and 
Table 2

In vitro anti-cancer activities of emodin.

\begin{tabular}{|c|c|c|}
\hline Cell lines & Mechanism(s) of action & Refs. \\
\hline 1. Human myeloid leukemia HL-60; jurkat cells & $\begin{array}{l}\text { Down-regulates AKT pathway; Induces apoptosis } \\
\text { Decreases Bcl-2, and procaspase-3, }-8 \text { and }-9 \text { expressions; increases caspase- } 3 \text { and PARP } \\
\text { expressions; induces apoptosis } \\
\text { Inhibits IL-6-induced JAK2/STAT3 pathway; induces apoptosis }\end{array}$ & $\begin{array}{l}{[71]} \\
{[74]} \\
{[6]}\end{array}$ \\
\hline $\begin{array}{l}\text { 2. Lung cancer H1703 or A549 cells; CH27; Human NIH-H460 } \\
\text { lung cancer cells and SMMC-7721 liver cancer cells }\end{array}$ & $\begin{array}{l}\text { Increases mitomycin C induced cytotoxicity via ERK1/2 inactivation and Rad51 down- } \\
\text { regulation } \\
\text { Induces apoptosis by Bax and Fas pathway } \\
\text { Inhibits retinoid X receptor transcription activity; induces apoptosis }\end{array}$ & $\begin{array}{l}{[53]} \\
{[79]} \\
{[99]}\end{array}$ \\
\hline $\begin{array}{l}\text { 3. Breast cancer cell MDA-MB-435; MCF-7/Adr cells; HSC5 } \\
\text { and MDA-MB-231 }\end{array}$ & 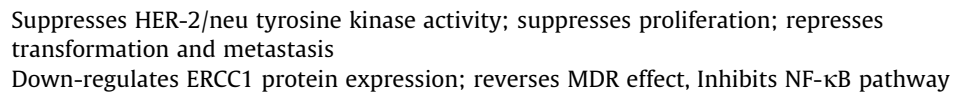 & $\begin{array}{l}{[49][51} \\
{[57][62}\end{array}$ \\
\hline 4. Human non-small cell lung cancer(NSCLC) cells & $\begin{array}{l}\text { Down-regulates ERCC1; ERK1/2 signaling pathway } \\
\text { Induces cytotoxicity by down-regulating the expression of Rad51 and ERCC1with or without } \\
\text { capecitabine }\end{array}$ & $\begin{array}{l}{[54]} \\
{[47][55}\end{array}$ \\
\hline 5.Esophagus cancer EC/CUHK1 cells; EC-109 & $\begin{array}{l}\text { Increases the ROS production; exhibits cytotoxic effects } \\
\text { Decreases intracellular pH; generates ROS; induces apoptosis }\end{array}$ & $\begin{array}{l}{[56]} \\
{[84]}\end{array}$ \\
\hline $\begin{array}{l}\text { 6. Prostate cancer DU-145 cells; DU145 and lung tumor cells } \\
\text { A549 cells; LNCap }\end{array}$ & $\begin{array}{l}\text { Co-treatment with cisplatin elevates the production of ROS and chemosensitivity; down- } \\
\text { regulates MDR1 gene, suppress HIF-1 } \alpha \text { expression } \\
\text { Inhibits CXCL12; down-regulates CXCR } 4 \text { and HER2 expression } \\
\text { Targets AR }\end{array}$ & $\begin{array}{l}{[58]} \\
{[109]} \\
{[61]}\end{array}$ \\
\hline 7. Ovarian cancer A2780/taxol cells & $\begin{array}{l}\text { Inhibits tumor growth; increases sensitivity of tumor cells to paclitaxel by down-regulating } \\
\text { Pgp, XIAP and survivin }\end{array}$ & [59] \\
\hline 8. Pancreatic cancer cells; SW1990 & $\begin{array}{l}\text { Inhibits NF- } \kappa B \text { and its regulated factors, VEGF, MMP-2, MMP-9, and eNOS } \\
\text { Inhibits proliferation; suppresses NF- } \kappa B \text {, survivin and MMP-9 proteins }\end{array}$ & $\begin{array}{l}{[104]} \\
{[41]}\end{array}$ \\
\hline $\begin{array}{l}\text { 9. Colon cancer cells WiDr; DLD-1, and SGC-7901 human } \\
\text { gastric carcinoma cell line }\end{array}$ & $\begin{array}{l}\text { Suppresses the NO-mediated up-regulation of MMP-2 and MMP-9 } \\
\text { Inhibits PRL-3 gene; inhibits cell proliferation }\end{array}$ & $\begin{array}{l}{[106]} \\
{[40]}\end{array}$ \\
\hline 10. Human neuroblastoma cancer SH-SY5Y cells & $\begin{array}{l}\text { Inhibits of migration and invasion; inhibits the levels of GRB2, RhoA, HIF-1 } \alpha \text {, VEGF, FAK, } \\
\text { iNOS, COX2, p-p38, p-c-jun, MMP2, MMP9 and MMP7 but promotes the levels of PKC, PI3K, } \\
\text { MEKK3 and NF- } \mathrm{B}(\mathrm{p} 65)\end{array}$ & [110] \\
\hline $\begin{array}{l}\text { 11. Huh7, Hep3B, and HepG2 cells; Hep3B and HeLa cells, } \\
\text { HepG2; HepG2; HeLa }\end{array}$ & $\begin{array}{l}\text { Reduces NF- } \kappa \mathrm{B} / \mathrm{p} 65 \text { protein level, Bcl-2expression; increases } \mathrm{p} 53 \text {, activates caspase- } 8 \text { and }-9 \\
\text { Inhibits CK2, (FasL)/Fas, (TNF)/TNF receptor and (TRAIL)/TRAIL receptor expression, induces } \\
\text { apoptosis } \\
\text { Generates ROS, activates caspase- } 9 \text { and caspase- } 3 \text {. Promotes arsenic induced apoptosis; } \\
\text { production of ROS; inhibits NF- } \kappa \mathrm{B} \text { activation }\end{array}$ & $\begin{array}{l}{[69]} \\
{[81][83} \\
{[86]}\end{array}$ \\
\hline 12. Microglia; Glioma & $\begin{array}{l}\text { Inhibits TRB3; induces apoptosis } \\
\text { Inhibits FAK, ERK1/2, activates AKT/PKB, inhibits AP-1 and NF- } \kappa B \text { transcription factors }\end{array}$ & $\begin{array}{l}{[85]} \\
{[46]}\end{array}$ \\
\hline
\end{tabular}

Mn-SOD (SOD2), which produce $\mathrm{H}_{2} \mathrm{O}_{2}$, were overexpressed in the DL cells. Enzymes such as catalase and glutathione peroxidase degrade the $\mathrm{H}_{2} \mathrm{O}_{2}$. With overproduction of $\mathrm{H}_{2} \mathrm{O}_{2}$, concentration of both these enzymes decreases considerably, indicating that emodin induces apoptosis via the mitochondrial pathway [112]. Chang et al. [113] showed that treatment with emodin can enhance phagocytic activity by monocytes and macrophages in the WEHI-3 leukemia murine model and also reduce liver and spleen weights. The potential of emodin to inhibit proliferation of K562 cell growth in vivo was shown by concomitant decrease in tumor volume and weight of xenografted tumor in nude mice. Moreover, emodin could also induce apoptosis by mitochondria-dependent activation of caspase- 3 and -9 and by up-regulating expression of Bax protein and down-regulating Bcl-2 protein expression [114]. Liu et al. [87] showed that emodin, given i.p. to orthotopically implanted nude mice at doses of $0,10,20,40,80 \mathrm{mg} / \mathrm{kg}, 5$ times every 3 days, induced the pancreatic cancer cell apoptosis via declining the mitochondrial membrane potential in a dose-dependent manner.

Emodin also exerts a potent anti-angiogenic effect in vivo, as verified from its inhibition of VEGF-A-induced neovascularization of matrigel plug implanted in mice and naturally induced neovascularization of capillary vessel formation of chick chorioallantoic membrane (CAM) [101]. Zhang et al. [115] showed that emodin functions as tyrosine kinase inhibitor. Emodin, together with taxol, synergistically inhibited tumor growth by $70 \%$ and prolonged survival by supressing tyrosine phosphorylation of p185neu in athymic mice bearing s.c. xenografts of human tumor cells. In
LS10345 xenograft models, $40 \mathrm{mg} / \mathrm{kg}$ of emodin given i.p. once every 3 days, resulted in $46 \%$ inhibition of tumor growth [67].

Our group also recently analyzed the ability of emodin to affect CXCR4 expression as well as function in HCC orthotopic HCC mouse model. We observed that emodin downregulated the expression of CXCR4 in a dose-and time-dependent manner in HCC cells. Treatment with pharmacological proteasome and lysosomal inhibitors did not have substantial effect on emodin-induced decrease in CXCR4 expression. When investigated for the molecular mechanism(s), it was observed that the suppression of CXCR4 expression was due to downregulation of mRNA expression, inhibition of NF- $\kappa B$ activation, and abrogation of chromatin immunoprecipitation activity. Inhibition of CXCR4 expression by emodin further correlated with the suppression of CXCL12-induced migration and invasion in HCC cell lines. In addition, emodin treatment significantly suppressed metastasis to the lungs in an orthotopic HCC mice model and CXCR4 expression in tumor tissues. Overall, our data also indicates that emodin exerts its anti-metastatic effect through the downregulation of CXCR4 expression and thus has the potential for the treatment of HCC [116].

In a subcutaneous xenograft pancreatic cancer, emodin augmented the therapeutic effect of gemcitabine. Interestingly, emodin also down-regulated the expression of survivin and $\beta$-catenin and decreases the translocation of $\beta$-catenin into nucleus [117]. In another study, Guo et al. [78] showed that in the PANC-1 pancreatic cancer xenograft model, co-treatment with emodin and gemcitabine resulted in significant reduction in tumor volumes, 
Table 3

In vivo anti-cancer effects of emodin.

\begin{tabular}{|c|c|c|c|}
\hline Cancer models & Mechanism(s) of action & Dose and route of administration & Refs. \\
\hline 1. Dalton's lymphoma & Decrease in $\mathrm{Bcl} 2 / \mathrm{Bax}$ ratio; induces apoptosis & $40 \mathrm{mg} / \mathrm{kg} /$ day i.p. & {$[112]$} \\
\hline 2. WEHI-3 leukemia murine model & Enhances phagocytic activity & $5,10 \mathrm{mg} / \mathrm{kg}$ i.p. for 2 weeks & [113] \\
\hline 3. K562 xenografted tumor & Decreases tumor volume and weight; induces apoptosis & $25,50,100 \mathrm{mg} / \mathrm{kg}$ i.p. for 12 days & [114] \\
\hline $\begin{array}{l}\text { 4. Pancreatic cancer panc- } 1 \text { nude mice } \\
\text { orthotopically implanted }\end{array}$ & Induces apoptosis via decline in mitochondrial membrane potential & $\begin{array}{l}10,20,40,80 \mu \mathrm{mol} / \mathrm{l}, 5 \text { times in every } \\
3 \text { days i.p. }\end{array}$ & {$[87]$} \\
\hline $\begin{array}{l}\text { 5. LS10345 tumor xenografts mice } \\
\text { models }\end{array}$ & Decreases tumor weight and volume & $40 \mathrm{mg} / \mathrm{kg}$ i.p. once every 3 days & [67] \\
\hline 6. Pancreatic cancer Bxpc-3 xenografts & $\begin{array}{l}\text { Augments therapeutic effect of gemcitabine; down-regulates the expression of } \\
\text { survivin and } \beta \text {-catenin }\end{array}$ & $40 \mathrm{mg} / \mathrm{kg}$ twice per week for 2 weeks & [117] \\
\hline $\begin{array}{l}\text { 7. Pancreatic cancer SW1990 } \\
\text { metastatic model }\end{array}$ & $\begin{array}{l}\text { Downregulates NF- } \mathrm{KB} \text {, survivin and MMP-9 expression; Inhibits tumor growth } \\
\text { and weight }\end{array}$ & $\begin{array}{l}20,40 \mathrm{mg} / \mathrm{kg} \text { intragastric incubation. } \\
\text { two weeks, thrice per week }\end{array}$ & [41] \\
\hline 8. EC/CUHK xenografts in nude & $\begin{array}{l}\text { With or without Arsenic; downregulates NF- } \kappa \mathrm{B} \text { expression, induces } \\
\text { mitochondria dependent apoptosis, decreases tumor weight and size }\end{array}$ & $20,30 \mathrm{mg} / \mathrm{kg} /$ day i.p. & [56] \\
\hline $\begin{array}{l}\text { 9. Pancreatic cancer xenograft tumor } \\
\text { model SW1990 cells }\end{array}$ & $\begin{array}{l}\text { Emodin and gemcitabine efficiently suppress tumor growth; Inhibits AKT and } \\
\text { NF- } \kappa B \text { pathways, induces apoptosis }\end{array}$ & $40 \mathrm{mg} / \mathrm{kg}$ emodin i.p. & [119] \\
\hline 10. BT-474 and MDA-MB-361 cells & Inhibits tumor growth and transformation and prolonged survival & $\begin{array}{l}40 \mathrm{mg} / \mathrm{kg} \text { i.p. injection twice a week } \\
\text { for } 8 \text { weeks }\end{array}$ & [115] \\
\hline $\begin{array}{l}\text { 11. Two-stage carcinogenesis test of } \\
\text { mouse skin tumors }\end{array}$ & Decreases papilloma numbers numbers & $0.0025 \%$ emodin in drinking water & [118] \\
\hline 12. PC3-AR xenografts in nude mice & Decreases tumor volume; Prolongs survival rate & $40 \mathrm{mg} / \mathrm{kg} / \mathrm{d}$ emodin, i.p. & [71] \\
\hline
\end{tabular}

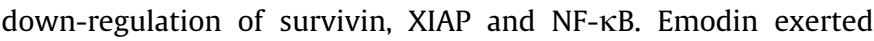
anti-proliferative and anti-metastatic activity on pancreatic cancer in vivo by down-regulation of NF- $\kappa \mathrm{B}$, survivin and MMP-9 expression [41]. The combination of emodin and arsenic promoted the major apoptotic signaling events, i.e., the collapse of the mitochondrial transmembrane potential, the release of cytochrome c, and the activation of caspases- 9 and -3 . It suppressed the activation of transcription factor NF- $\mathrm{BB}$ and survivin [56]. It was also shown that emodin exhibited potent inhibitory activity in the two-stage carcinogenesis test of mouse skin tumors induced by nitric oxide

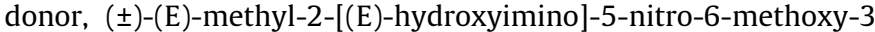
hexeneamide as an initiator and 12-O-tetradecanoylphorbol-13acetate as a promoter [118]. Wei et al. demonstrated that co-treatment of emodin and gemcitabine inhibited pancreatic adenocarcinoma tumor growth. This combination suppressed AKT and NF- $\kappa B$ pathways and thereby promoted the mitochondrial dependent apoptotic pathway in vivo [119]. The anticancer effects of emodin in various in vivo models, including its dosing regimen in each study, are summarized in Table 3.

\section{Perspectives and conclusions}

Overall, this review summarizes the evidence which indicates that emodin can modulate a diverse array of molecular targets and thus has a great potential to be used as a therapeutic agent for a variety of inflammatory conditions and cancer. Emodin strongly inhibits several kinases, such as Her-2/neu, CKII, and PKC. It also affects NF- $\kappa \mathrm{B}$, STAT3, AKT, MMPs and Bax/Bcl-2 signaling pathways. Moreover, emodin in conjunction with various chemotherapeutic agents and targeted therapies has been found to be effective in the elimination/retardation of growth of tumor cells. Also, the evidence provided strongly supports the ability of emodin to inhibit diverse events involved in tumor initiation, progression and metastasis and clearly vindicates its traditional use since ancient times in the treatment of inflammatory diseases/cancers. Novel molecular targets of emodin identified in last few years have begun to reveal additional therapeutic uses of this drug. However, only limited data related to the bioavailability, pharmacokinetics, and metabolism of emodin is available till now. Whether emodin affects the metabolism of other pharmacological drugs needs to be evaluated before it can be safely used in combination with other drugs. Hence more work needs to be done to fully translate the ob- served preclinical findings with this important natural agent in well designed human clinical trials.

\section{Conflict of Interest}

We declare that none of the authors have financial interest related to this work.

\section{Acknowledgments}

This research work was supported by grant from Singapore Ministry of Health's National Medical Research Council under its Exploratory/Developmental Grant (EDG) funding scheme to GS. KSA was supported by the Korea Science and Engineering Foundation (KOSEF) grant funded by the Korean Ministry of Education, Science and Technology (MoEST) (No. 2011-0006220). APK was supported by grants from Singapore Ministry of Education Tier 2 [MOE 2012-T2-2-139], Academic Research Fund Tier 1 [R-184000-228-112] and Cancer Science Institute of Singapore, Experimental Therapeutics I Program [Grant R-713-001-011-271].

\section{References}

[1] A.B. Kunnumakkara, P. Anand, B.B. Aggarwal, Curcumin inhibits proliferation, invasion, angiogenesis and metastasis of different cancers through interaction with multiple cell signaling proteins, Cancer Lett. 269 (2008) 199-225.

[2] W. Tan, J. Lu, M. Huang, Y. Li, M. Chen, G. Wu, J. Gong, Z. Zhong, Z. Xu, Y. Dang J. Guo, X. Chen, Y. Wang, Anti-cancer natural products isolated from chinese medicinal herbs, Chin. Med. 6 (2011) 27.

[3] G. Szakacs, J.K. Paterson, J.A. Ludwig, C. Booth-Genthe, M.M. Gottesman, Targeting multidrug resistance in cancer, Nat. Rev. Drug Discov. 5 (2006) 219-234.

[4] X.Y. Shang, Z.B. Yuan, Determination of six effective components in Rheum by cyclodextrin modified micellar electrokinetic chromatography, Yao Xue Xue Bao 37 (2002) 798-801.

[5] S. Xiaoyu, Y. Zhuobin, Determination of active components in rhubarb by cyclodextrin-modified capillary zone electrophoresis, Sensors 1 (2001) 229235.

[6] A. Muto, M. Hori, Y. Sasaki, A. Saitoh, I. Yasuda, T. Maekawa, T. Uchida, K Asakura, T. Nakazato, T. Kaneda, M. Kizaki, Y. Ikeda, T. Yoshida, Emodin has a cytotoxic activity against human multiple myeloma as a Janus-activated kinase 2 inhibitor, Mol. Cancer Ther. 6 (2007) 987-994.

[7] A. Kumar, S. Dhawan, B.B. Aggarwal, Emodin (3-methyl-1,6,8trihydroxyanthraquinone) inhibits TNF-induced NF-kappaB activation, IkappaB degradation, and expression of cell surface adhesion proteins in human vascular endothelial cells, Oncogene 17 (1998) 913-918.

[8] G. Meng, Y. Liu, C. Lou, H. Yang, Emodin suppresses lipopolysaccharideinduced pro-inflammatory responses and NF-kappaB activation by disrupting lipid rafts in CD14-negative endothelial cells, Brit. J. Pharmacol. 161 (2010) 1628-1644. 
[9] Y.C. Kuo, H.C. Meng, W.J. Tsai, Regulation of cell proliferation, inflammatory cytokine production and calcium mobilization in primary human $\mathrm{T}$ lymphocytes by emodin from Polygonum hypoleucum Ohwi, Inflamm. Res. 50 (2001) 73-82.

[10] W. Zhang, H. Li, H. Bu, H. Chen, H. Tong, D. Liu, H. Guo, S.Z. Lin, Emodin inhibits the differentiation and maturation of dendritic cells and increases the production of regulatory T cells, Int. J. Mol. Med. 29 (2012) 159-164.

[11] M.Y. Shen, Y.J. Liu, M.J. Don, H.Y. Liu, Z.W. Chen, C. Mettling, P. Corbeau, C.K Chiang, Y.S. Jang, T.H. Li, P. Young, C.L. Chang, Y.L. Lin, W.C. Yang, Combined phytochemistry and chemotaxis assays for identification and mechanistic analysis of anti-inflammatory phytochemicals in Fallopia japonica, PLoS ONE 6 (2011) e27480.

[12] F.S. Yu, C.S. Yu, J.K. Chan, H.M. Kuo, J.P. Lin, N.Y. Tang, Y.H. Chang, J.G. Chung, The effects of emodin on the expression of cytokines and functions of leukocytes from Sprague-Dawley rats, In Vivo 20 (2006) 147-151.

[13] H.L. Li, H.L. Chen, H. Li, K.L. Zhang, X.Y. Chen, X.W. Wang, Q.Y. Kong, J. Liu, Regulatory effects of emodin on NF-kappaB activation and inflammatory cytokine expression in RAW 264.7 macrophages, Int. J. Mol. Med. 16 (2005) 41-47.

[14] W. Lee, S.K. Ku, T.H. Kim, J.S. Bae, Emodin-6-O-beta-d-glucoside inhibits HMGB1-induced inflammatory responses in vitro and in vivo, Food Chem. Toxicol. 52C (2012) 97-104.

[15] X.M. Xia, B.K. Li, S.M. Xing, H.L. Ruan, Emodin promoted pancreatic claudin-5 and occludin expression in experimental acute pancreatitis rats, World J. Gastroentero. 18 (2012) 2132-2139.

[16] J.X. Wu, J.Y. Xu, Y.Z. Yuan, Effects and mechanism of emodin and sandostatin on pancreatic ischemia in acute haemorrhagic necrotizing pancreatitis Zhongguo Zhong Xi Yi Jie He Za Zhi 17 (1997) 356-359.

[17] K.X. Lou, Z.H. Gong, Y.Z. Yuan, Study on effect of emodin on TGF beta 1 expression in pancreatic tissue of rats suffering from acute pancreatitis, Zhongguo Zhong Xi Yi Jie He Za Zhi 21 (2001) 433-436.

[18] Y.H. Li, F.Q. He, Z.W. Huang, P. Xue, Q. Xia, Protective effects of emodin on intestinal lesion in rat model with acute necrotizing pancreatitis, Sichuan Da Xue Xue Bao Yi Xue Ban 41 (2010) 1012-1015.

[19] Z. Gong, Y. Yuan, K. Lou, S. Tu, Z. Zhai, J. Xu, Mechanisms of Chinese herb emodin and somatostatin analogs on pancreatic regeneration in acute pancreatitis in rats, Pancreas 25 (2002) 154-160.

[20] Z. Li, X. Xia, S. Zhang, A. Zhang, W. Bo, R. Zhou, Up-regulation of Toll-like receptor 4 was suppressed by emodin and baicalin in the setting of acute pancreatitis, Biomed. Pharmacother. 63 (2009) 120-128.

[21] Z.F. Li, X.M. Xia, C. Huang, S. Zhang, J. Zhang, A.J. Zhang, Emodin and baicalein inhibit pancreatic stromal derived factor-1 expression in rats with acute pancreatitis, Hepatobiliary Pancreat Dis. Int. 8 (2009) 201-208.

[22] M.K. Ha, Y.H. Song, S.J. Jeong, H.J. Lee, J.H. Jung, B. Kim, H.S. Song, J.E. Huh, S.H. $\mathrm{Kim}$, Emodin inhibits proinflammatory responses and inactivates histone deacetylase 1 in hypoxic rheumatoid synoviocytes, Biol. Pharm. Bull. 34 (2011) 1432-1437.

[23] M.X. Xiang, Z. Xu, H.W. Su, J. Hu, Y.J. Yan, Emodin-8-O-beta-D-glucoside from Polygonum amplexicaule D. Don var. sinense Forb. promotes proliferation and differentiation of osteoblastic MC3T3-E1 cells, Molecules 16 (2011) 728737.

[24] X. Chu, M. Wei, X. Yang, Q. Cao, X. Xie, M. Guan, D. Wang, X. Deng, Effects of an anthraquinone derivative from Rheum officinale Baill, emodin, on airway responses in a murine model of asthma, Food Chem. Toxicol. 50 (2012) 23682375.

[25] Y. Lu, J.H. Yang, X. Li, K. Hwangbo, S.L. Hwang, Y. Taketomi, M. Murakami, Y.C Chang, C.H. Kim, J.K. Son, H.W. Chang, Emodin, a naturally occurring anthraquinone derivative, suppresses IgE-mediated anaphylactic reaction and mast cell activation, Biochem. Pharmacol. 82 (2011) 1700-1708.

[26] Jason Ryan, D.J. Cohen, Diagnosis and Treatment of Vulnerable Plaque, 2006.

[27] M. Zhou, H. Xu, L. Pan, J. Wen, Y. Guo, K. Chen, Emodin promotes atherosclerotic plaque stability in fat-fed apolipoprotein E-deficient mice, Tohoku J. Exp. Med. 215 (2008) 61-69.

[28] L. Meng, D. Yan, W. Xu, J. Ma, B. Chen, H. Feng, Emodin inhibits tumor necrosis factor-alpha-induced migration and inflammatory responses in rat aortic smooth muscle cells, Int. J. Mol. Med. 29 (2012) 999-1006.

[29] S.K. Heo, H.J. Yun, W.H. Park, S.D. Park, Emodin inhibits TNF-alpha-induced human aortic smooth-muscle cell proliferation via caspase- and mitochondrial-dependent apoptosis, J. Cell. Biochem. 105 (2008) 70-80.

[30] S.K. Heo, H.J. Yun, E.K. Noh, S.D. Park, Emodin and rhein inhibit LIGHTinduced monocytes migration by blocking of ROS production, Vascul. Pharmacol. 53 (2010) 28-37.

[31] Q. Gao, F. Wang, S. Guo, J. Li, B. Zhu, J. Cheng, Y. Jin, B. Li, H. Wang, S. Shi, Q. Gao, Z. Zhang, W. Cao, Y. Tian, Sonodynamic effect of an anti-inflammatory agent-emodin on macrophages, Ultrasound Med. Biol. 37 (2011) $1478-1485$.

[32] Z.C. Song, Z.S. Wang, J.H. Bai, Z. Li, J. Hu, Emodin, a naturally occurring anthraquinone, ameliorates experimental autoimmune myocarditis in rats, Tohoku J. Exp. Med. 227 (2012) 225-230.

[33] Y. Wu, X. Tu, G. Lin, H. Xia, H. Huang, J. Wan, Z. Cheng, M. Liu, G. Chen, H. Zhang, J. Fu, Q. Liu, D.X. Liu, Emodin-mediated protection from acute myocardial infarction via inhibition of inflammation and apoptosis in local ischemic myocardium, Life Sci. 81 (2007) 1332-1338.

[34] M. Yamada, S. Katsuma, T. Adachi, A. Hirasawa, S. Shiojima, T. Kadowaki, Y. Okuno, T.A. Koshimizu, S. Fujii, Y. Sekiya, Y. Miyamoto, M. Tamura, W. Yumura, H. Nihei, M. Kobayashi, G. Tsujimoto, Inhibition of protein kinase
CK2 prevents the progression of glomerulonephritis, Proc. Natl. Acad. Sci. USA 102 (2005) 7736-7741.

[35] J. Wei, L. Ni, J. Yao, Experimental treatment of rhubarb on mesangioproliferative glomerulonephritis in rats, Zhonghua Nei Ke Za Zhi 36 (1997) 87-89.

[36] G. Liu, R. Ye, Z. Tan, Effect of emodin on fibroblasts in lupus nephritis, Zhongguo Zhong Xi Yi Jie He Za Zhi 20 (2000) 196-198.

[37] M. Pickhardt, Z. Gazova, M. von Bergen, I. Khlistunova, Y. Wang, A. Hascher, E.M. Mandelkow, J. Biernat, E. Mandelkow, Anthraquinones inhibit tau aggregation and dissolve Alzheimer's paired helical filaments in vitro and in cells, J. Biol. Chem. 280 (2005) 3628-3635.

[38] T. Liu, H. Jin, Q.R. Sun, J.H. Xu, H.T. Hu, Neuroprotective effects of emodin in rat cortical neurons against beta-amyloid-induced neurotoxicity, Brain Res. 1347 (2010) 149-160.

[39] S.C. Wang, L. Zhang, G.N. Hortobagyi, M.C. Hung, Targeting HER2: recent developments and future directions for breast cancer patients, Semin. Oncol. 28 (2001) 21-29.

[40] Z.H. Sun, P. Bu, Downregulation of phosphatase of regenerating liver-3 is involved in the inhibition of proliferation and apoptosis induced by emodin in the SGC-7901 human gastric carcinoma cell line, Exp. Therm. Med. 3 (2012) 1077-1081.

[41] A. Liu, H. Chen, W. Wei, S. Ye, W. Liao, J. Gong, Z. Jiang, L. Wang, S. Lin, Antiproliferative and antimetastatic effects of emodin on human pancreatic cancer, Oncol. Rep. 26 (2011) 81-89.

[42] J.N. Li, F.Z. Lv, J.L. Xiao, Effects of emodin on proliferation cycle and apoptotic gene of human lung adenocarcinoma cell line Anip 973, Zhongguo Zhong Xi Yi Jie He Za Zhi 26 (2006) 1015-1017. 1020.

[43] C.X. Yu, X.Q. Zhang, L.D. Kang, P.J. Zhang, W.W. Chen, W.W. Liu, Q.W. Liu, J.Y. Zhang, Emodin induces apoptosis in human prostate cancer cell LNCaP, Asian J. Androl. 10 (2008) 625-634.

[44] J.B. Liu, X.G. Gao, T. Lian, A.Z. Zhao, K.Z. Li, Apoptosis of human hepatoma HepG2 cells induced by emodin in vitro, Ai Zheng 22 (2003) 1280-1283.

[45] C.M. Hsu, Y.A. Hsu, Y. Tsai, F.K. Shieh, S.H. Huang, L. Wan, F.J. Tsai, Emodin inhibits the growth of hepatoma cells: finding the common anti-cancer pathway using Huh7, Hep3B, and HepG2 cells, Biochem. Biophys. Res. Commun. 392 (2010) 473-478.

[46] M.S. Kim, M.J. Park, S.J. Kim, C.H. Lee, H. Yoo, S.H. Shin, E.S. Song, S.H. Lee Emodin suppresses hyaluronic acid-induced MMP-9 secretion and invasion of glioma cells, Int. J. Oncol. 27 (2005) 839-846.

[47] L. He, J.J. Bi, Q. Guo, Y. Yu, X.F. Ye, Effects of emodin extracted from Chinese herbs on proliferation of non-small cell lung cancer and underlying mechanisms, Asian Pac. J. Cancer Prev. 13 (2012) 1505-1510.

[48] X. Zhou, B. Song, L. Jin, D. Hu, C. Diao, G. Xu, Z. Zou, S. Yang, Isolation and inhibitory activity against ERK phosphorylation of hydroxyanthraquinones from rhubarb, Bioorg. Med. Chem. Lett. 16 (2006) 563-568.

[49] N. Ueno, N. Kiyokawa, M. Hung, Growth suppression of low HER-2/neuexpressing breast cancer cell line MDA-MB-435 by tyrosine kinase inhibitor emodin, Oncol. Rep. 3 (1996) 509-511.

[50] L. Zhang, M.C. Hung, Sensitization of HER-2/neu-overexpressing non-small cell lung cancer cells to chemotherapeutic drugs by tyrosine kinase inhibitor emodin, Oncogene 12 (1996) 571-576.

[51] L. Zhang, Y.K. Lau, L. Xi, R.L. Hong, D.S. Kim, C.F. Chen, G.N. Hortobagyi, C. Chang, M.C. Hung, Tyrosine kinase inhibitors, emodin and its derivative repress HER-2/neu-induced cellular transformation and metastasisassociated properties, Oncogene 16 (1998) 2855-2863.

[52] Y. Lu, J. Zhang, J. Qian, The effect of emodin on VEGF receptors in human colon cancer cells, Cancer Biother. Radiopharm. 23 (2008) 222-228.

[53] Y.J. Su, M.S. Tsai, Y.H. Kuo, Y.F. Chiu, C.M. Cheng, S.T. Lin, Y.W. Lin, Role of Rad51 down-regulation and extracellular signal-regulated kinases 1 and 2 inactivation in emodin and mitomycin C-induced synergistic cytotoxicity in human non-small-cell lung cancer cells, Mol. Pharmacol. 77 (2010) 633-643.

[54] J.C. Ko, Y.J. Su, S.T. Lin, J.Y. Jhan, S.C. Ciou, C.M. Cheng, Y.F. Chiu, Y.H. Kuo, M.S. Tsai, Y.W. Lin, Emodin enhances cisplatin-induced cytotoxicity via downregulation of ERCC1 and inactivation of ERK1/2, Lung Cancer 69 (2010) 155164.

[55] J.C. Ko, M.S. Tsai, Y.H. Kuo, Y.F. Chiu, S.H. Weng, Y.C. Su, Y.W. Lin, Modulation of Rad51, ERCC1, and thymidine phosphorylase by emodin result in synergistic cytotoxic effect in combination with capecitabine, Biochem. Pharmacol. 81 (2011) 680-690.

[56] J. Yang, H. Li, Y.Y. Chen, X.J. Wang, G.Y. Shi, Q.S. Hu, X.L. Kang, Y. Lu, X.M. Tang, Q.S. Guo, J. Yi, Anthraquinones sensitize tumor cells to arsenic cytotoxicity in vitro and in vivo via reactive oxygen species-mediated dual regulation of apoptosis, Free Radic. Biol. Med. 37 (2004) 2027-2041.

[57] J.M. Fu, J. Zhou, J. Shi, J.S. Xie, L. Huang, A.Y. Yip, W.T. Loo, L.W. Chow, E.L. Ng, Emodin affects ERCC1 expression in breast cancer cells, J. Trans. Med. 10 (Suppl 1) (2012) S7.

[58] X.Z. Huang, J. Wang, C. Huang, Y.Y. Chen, G.Y. Shi, Q.S. Hu, J. Yi, Emodin enhances cytotoxicity of chemotherapeutic drugs in prostate cancer cells: the mechanisms involve ROS-mediated suppression of multidrug resistance and hypoxia inducible factor-1, Cancer Biol. Ther. 7 (2008) 468-475.

[59] J. Li, P. Liu, H. Mao, A. Wanga, X. Zhang, Emodin sensitizes paclitaxel-resistant human ovarian cancer cells to paclitaxel-induced apoptosis in vitro, Oncol. Rep. 21 (2009) 1605-1610.

[60] T.L. Cha, L. Qiu, C.T. Chen, Y. Wen, M.C. Hung, Emodin down-regulates androgen receptor and inhibits prostate cancer cell growth, Cancer Res. 65 (2005) 2287-2295. 
[61] S. Masaldan, V.V. Iyer, Exploration of effects of emodin in selected cancer cell lines: enhanced growth inhibition by ascorbic acid and regulation of LRP1 and AR under hypoxia-like conditions, J. Appl. Toxicol. 3 (2012).

[62] Q. Huang, H.M. Shen, C.N. Ong, Inhibitory effect of emodin on tumor invasion through suppression of activator protein-1 and nuclear factor-kappaB, Biochem. Pharmacol. 68 (2004) 361-371.

[63] S.Y. Lin, W.W. Lai, C.C. Ho, F.S. Yu, G.W. Chen, J.S. Yang, K.C. Liu, M.L. Lin, P.P. Wu, M.J. Fan, J.G. Chung, Emodin induces apoptosis of human tongue squamous cancer SCC-4 cells through reactive oxygen species and mitochondria-dependent pathways, Anticancer Res. 29 (2009) 327-335.

[64] Z. Huang, G. Chen, P. Shi, Emodin-induced apoptosis in human breast cancer BCap-37 cells through the mitochondrial signaling pathway, Arch. Pharm. Res. 31 (2008) 742-748.

[65] Y.T. Su, H.L. Chang, S.K. Shyue, S.L. Hsu, Emodin induces apoptosis in human lung adenocarcinoma cells through a reactive oxygen species-dependent mitochondrial signaling pathway, Biochem. Pharmacol. 70 (2005) 229-241.

[66] G. Srinivas, R.J. Anto, P. Srinivas, S. Vidhyalakshmi, V.P. Senan, D. Karunagaran, Emodin induces apoptosis of human cervical cancer cells through poly(ADP-ribose) polymerase cleavage and activation of caspase-9, Eur. J. Pharmacol. 473 (2003) 117-125.

[67] Y.S. Ma, S.W. Weng, M.W. Lin, C.C. Lu, J.H. Chiang, J.S. Yang, K.C. Lai, J.P. Lin, N.Y. Tang, J.G. Lin, J.G. Chung, Antitumor effects of emodin on LS1034 human colon cancer cells in vitro and in vivo: roles of apoptotic cell death and LS1034 tumor xenografts model, Food Chem. Toxicol. 50 (2012) 1271-1278.

[68] J.M. Lai, J.T. Chang, C.L. Wen, S.L. Hsu, Emodin induces a reactive oxygen species-dependent and ATM-p53-Bax mediated cytotoxicity in lung cancer cells, Eur. J. Pharmacol. 623 (2009) 1-9.

[69] J.Q. Yu, W. Bao, J.C. Lei, Emodin regulates apoptotic pathway in human liver cancer cells, Phytother Res. (2012).

[70] D.E. Shieh, Y.Y. Chen, M.H. Yen, L.C. Chiang, C.C. Lin, Emodin-induced apoptosis through p53-dependent pathway in human hepatoma cells, Life Sci. 74 (2004) 2279-2290.

[71] H.Y. Zheng, J.D. Hu, Z.H. Zheng, L.Y. Huang, Y.Y. Chen, J. Zheng, X.J. Chen, L.H. Lu, Emodin induces leukemic HL-60 cells apoptosis probably by inhibiting Akt signal pathway, Yao Xue Xue Bao 42 (2007) 1142-1146.

[72] H. Kamei, T. Koide, T. Kojima, Y. Hashimoto, M. Hasegawa, Inhibition of cell growth in culture by quinones, Cancer Biother. Radiopharm. 13 (1998) 185-188.

[73] L. Zhang, C.J. Chang, S.S. Bacus, M.C. Hung, Suppressed transformation and induced differentiation of HER-2/neu-overexpressing breast cancer cells by emodin, Cancer Res. 55 (1995) 3890-3896.

[74] T.N. Wei, J.D. Hu, Y.Y. Chen, X.J. Chen, T.B. Liu, L.H. Lu, Effect of emodin on induction of apoptosis in jurkat cells and its possible mechanisms, Zhongguo Shi Yan Xue Ye Xue Za Zhi 17 (2009) 1203-1206.

[75] A. Subramaniam, M.K. Shanmugam, T.H. Ong, F. Li, E. Perumal, L. Chen, S. Vali, T. Abbasi, S. Kapoor, K.S. Ahn, A.P. Kumar, K.M. Hui, G. Sethi, The deactivation of signal transducer and activator of transcription-3 activation signaling by emodin inhibits growth and induces apoptosis in orthotopic hepatocellular carcinoma model, Brit. J. Pharmacol. (2013).

[76] L.Y. Huang, J.D. Hu, X.J. Chen, L.F. Zhu, H.L. Hu, Effects of emodin on the proliferation inhibition and apoptosis induction in HL-60 cells and the involvement of c-myc gene, Zhonghua Xue Ye Xue Za Zhi 26 (2005) 348-351.

[77] Z.H. Zheng, J.D. Hu, Y.Y. Chen, X.L. Lian, H.Y. Zheng, J. Zheng, M.H. Lin, Effect of emodin on proliferation inhibition and apoptosis induction in leukemic K562 cells, Zhongguo Shi Yan Xue Ye Xue Za Zhi 17 (2009) 1434-1438.

[78] H.C. Guo, H.Q. Bu, J. Luo, W.T. Wei, D.L. Liu, H. Chen, H.F. Tong, Z.H. Wang, H.Y. Wu, H.H. Li, M.M. Zuo, W. Li, S.Z. Lin, Emodin potentiates the antitumor effects of gemcitabine in PANC-1 pancreatic cancer xenograft model in vivo via inhibition of inhibitors of apoptosis, Int. J. Oncol. 40 (2012) 1849-1857.

[79] H.Z. Lee, Effects and mechanisms of emodin on cell death in human lung squamous cell carcinoma, Brit. J. Pharmacol. 134 (2001) 11-20.

[80] Y.C. Chen, S.C. Shen, W.R. Lee, F.L. Hsu, H.Y. Lin, C.H. Ko, S.W. Tseng, Emodin induces apoptosis in human promyeloleukemic HL-60 cells accompanied by activation of caspase 3 cascade but independent of reactive oxygen species production, Biochem. Pharmacol. 64 (2002) 1713-1724.

[81] H.R. Kim, K. Kim, K.H. Lee, S.J. Kim, J. Kim, Inhibition of casein kinase 2 enhances the death ligand- and natural kiler cell-induced hepatocellular carcinoma cell death, Clin. Exp. Immunol. 152 (2008) 336-344.

[82] A. Subramaniam, S.Y. Loo, P. Rajendran, K.A. Manu, E. Perumal, F. Li, M.K. Shanmugam, K.S. Siveen, J.I. Park, K.S. Ahn, K.M. Hui, A.P. Kumar, G. Sethi, An anthraquinone derivative, emodin sensitizes hepatocellular carcinoma cells to TRAIL induced apoptosis through the induction of death receptors and downregulation of cell survival proteins, Apoptosis (2013).

[83] X. Jing, N. Ueki, J. Cheng, H. Imanishi, T. Hada, Induction of apoptosis in hepatocellular carcinoma cell lines by emodin, Jpn. J. Cancer Res. 93 (2002) 874-882.

[84] Q.J. Wang, X.B. Cai, M.H. Liu, H. Hu, X.J. Tan, X.B. Jing, Apoptosis induced by emodin is associated with alterations of intracellular acidification and reactive oxygen species in EC-109 cells, Biochem. Cell Biol. 88 (2010) 767774 .

[85] Y. Yan, X. Su, Y. Liang, J. Zhang, C. Shi, Y. Lu, L. Gu, L. Fu, Emodin azide methyl anthraquinone derivative triggers mitochondrial-dependent cell apoptosis involving in caspase-8-mediated Bid cleavage, Mol. Cancer Ther. 7 (2008) 1688-1697.

[86] J. Yang, X.M. Tang, H. Li, G.Y. Shi, P. Zhu, H.F. Jin, J. Yi, Emodin sensitizes HeLa cell to arsenic trioxide induced apoptosis via the reactive oxygen speciesmediated signaling pathways, Shi Yan Sheng Wu Xue Bao 36 (2003) 465-475.
[87] J.X. Liu, J.H. Zhang, H.H. Li, F.J. Lai, K.J. Chen, H. Chen, J. Luo, H.C. Guo, Z.H. Wang, S.Z. Lin, Emodin induces Panc-1 cell apoptosis via declining the mitochondrial membrane potential, Oncol. Rep. 28 (2012) 1991-1996.

[88] J.A. Fresno Vara, E. Casado, J. de Castro, P. Cejas, C. Belda-Iniesta, M. GonzalezBaron, PI3K/Akt signalling pathway and cancer, Cancer Treat. Rev. 30 (2004) 193-204.

[89] K.Y. Kim, H.K. Shin, J.H. Lee, C.D. Kim, W.S. Lee, B.Y. Rhim, Y.W. Shin, K.W. Hong, Cilostazol enhances casein kinase 2 phosphorylation and suppresses tumor necrosis factor-alpha-induced increased phosphatase and tensin homolog deleted from chromosome 10 phosphorylation and apoptotic cell death in SK-N-SH cells, J. Pharmacol. Exp. Ther. 308 (2004) 97-104.

[90] G.H. Lai, Z. Zhang, A.E. Sirica, Celecoxib acts in a cyclooxygenase-2independent manner and in synergy with emodin to suppress rat cholangiocarcinoma growth in vitro through a mechanism involving enhanced Akt inactivation and increased activation of caspases-9 and -3 , Mol. Cancer Ther. 2 (2003) 265-271.

[91] B.B. Olsen, M. Bjorling-Poulsen, B. Guerra, Emodin negatively affects the phosphoinositide 3-kinase/AKT signalling pathway: a study on its mechanism of action, Int. J. Biochem. Cell Biol. 39 (2007) 227-237.

[92] Y.Y. Yan, L.S. Zheng, X. Zhang, L.K. Chen, S. Singh, F. Wang, J.Y. Zhang, Y.J Liang, C.L. Dai, L.Q. Gu, M.S. Zeng, T.T. Talele, Z.S. Chen, L.W. Fu, Blockade of Her2/neu binding to Hsp90 by emodin azide methyl anthraquinone derivative induces proteasomal degradation of Her2/neu, Mol. Pharm. 8 (2011) 1687-1697.

[93] K. Hwangbo, M.S. Zheng, Y.J. Kim, J.Y. Im, C.S. Lee, M.H. Woo, Y. Jahng, H.W. Chang, J.K. Son, Inhibition of DNA topoisomerases I and II of compounds from Reynoutria japonica, Arch. Pharm. Res. 35 (2012) 1583-1589.

[94] S.O. Muller, I. Eckert, W.K. Lutz, H. Stopper, Genotoxicity of the laxative drug components emodin, aloe-emodin and danthron in mammalian cells: topoisomerase II mediated?, Mutat Res. 371 (1996) 165-173.

[95] X.B. Kong, L. Rubin, L.I. Chen, G. Ciszewska, K.A. Watanabe, W.P. Tong, F.M Sirotnak, T.C. Chou, Topoisomerase II-mediated DNA cleavage activity and irreversibility of cleavable complex formation induced by DNA intercalator with alkylating capability, Mol. Pharmacol. 41 (1992) 237-244.

[96] S.O. Mueller, H. Stopper, Characterization of the genotoxicity of anthraquinones in mammalian cells, Biochim. Biophys. Acta 1428 (1999) 406-414.

[97] Y. Li, Y. Luan, X. Qi, M. Li, L. Gong, X. Xue, X. Wu, Y. Wu, M. Chen, G. Xing, J. Yao, J. Ren, Emodin triggers DNA double-strand breaks by stabilizing topoisomerase II-DNA cleavage complexes and by inhibiting ATP hydrolysis of topoisomerase II, Toxicol. Sci. 118 (2010) 435-443.

[98] H.W. Wang, T.L. Chen, P.C. Yang, T.H. Ueng, Induction of cytochromes P450 $1 \mathrm{~A} 1$ and $1 \mathrm{~B} 1$ by emodin in human lung adenocarcinoma cell line CL5, Drug Metab. Dispos. 29 (2001) 1229-1235.

[99] F.L. He, L. Wang, X.K. Zhang, J.Z. Zeng, Emodin induces apoptosis of cancer cells and inhibits retinoid $\mathrm{X}$ receptor transcriptional activity, Yao Xue Xue Bao 43 (2008) 350-355.

[100] K.S. Radha, H.K. Madhyastha, Y. Nakajima, S. Omura, M. Maruyama, Emodin upregulates urokinase plasminogen activator, plasminogen activator inhibitor-1 and promotes wound healing in human fibroblasts, Vascl. Pharmacol. 48 (2008) 184-190.

[101] H.J. Kwak, M.J. Park, C.M. Park, S.I. Moon, D.H. Yoo, H.C. Lee, S.H. Lee, M.S. Kim, H.W. Lee, W.S. Shin, I.C. Park, C.H. Rhee, S.I. Hong, Emodin inhibits vascular endothelial growth factor-A-induced angiogenesis by blocking receptor-2 (KDR/Flk-1) phosphorylation, Int. J. Cancer 118 (2006) 2711-2720.

[102] X.H. Wang, S.Y. Wu, Y.S. Zhen, Inhibitory effects of emodin on angiogenesis, Yao Xue Xue Bao 39 (2004) 254-258.

[103] C. Braumann, J. Tangermann, C.A. Jacobi, J.M. Muller, W. Dubiel, Novel antiangiogenic compounds for application in tumor therapy - COPS signalosome-associated kinases as possible targets, Mini Rev. Med. Chem. 8 (2008) 421-428.

[104] S.Z. Lin, W.T. Wei, H. Chen, K.J. Chen, H.F. Tong, Z.H. Wang, Z.L. Ni, H.B. Liu, H.C. Guo, D.L. Liu, Antitumor activity of emodin against pancreatic cancer depends on its dual role: promotion of apoptosis and suppression of angiogenesis, PLoS ONE 7 (2012) e42146.

[105] T. Kaneshiro, T. Morioka, M. Inamine, T. Kinjo, J. Arakaki, I. Chiba, N. Sunagawa, M. Suzui, N. Yoshimi, Anthraquinone derivative emodin inhibits tumor-associated angiogenesis through inhibition of extracellular signal-regulated kinase 1/2 phosphorylation, Eur. J. Pharmacol. 553 (2006) 46-53.

[106] U. Damodharan, R. Ganesan, U.C. Radhakrishnan, Expression of MMP2 and MMP9 (gelatinases A and B) in human colon cancer cells, Appl. Biochem. Biotechnol. 165 (2011) 1245-1252.

[107] J. Lee, E. Jung, J. Lee, S. Huh, C.H. Hwang, H.Y. Lee, E.J. Kim, J.M. Cheon, C.G. Hyun, Y.S. Kim, D. Park, Emodin inhibits TNF alpha-induced MMP-1 expression through suppression of activator protein-1 (AP-1), Life Sci. 79 (2006) 2480-2485.

[108] K.A. Manu, M.K. Shanmugam, P. Rajendran, F. Li, L. Ramachandran, H.S. Hay, R. Kannaiyan, S.N. Swamy, S. Vali, S. Kapoor, B. Ramesh, P. Bist, E.S. Koay, L.H. Lim, K.S. Ahn, A.P. Kumar, G. Sethi, Plumbagin inhibits invasion and migration of breast and gastric cancer cells by downregulating the expression of chemokine receptor CXCR4, Mol. Cancer 10 (2011) 107.

[109] S. Ok, S.M. Kim, C. Kim, D. Nam, B.S. Shim, S.H. Kim, K.S. Ahn, S.H. Choi, K.S. Ahn, Emodin inhibits invasion and migration of prostate and lung cancer cells by downregulating the expression of chemokine receptor CXCR4 Immunopharmacol. Immunotoxicol. 34 (2012) 768-778. 
[110] H.F. Lu, K.C. Lai, S.C. Hsu, H.J. Lin, C.L. Kuo, C.L. Liao, J.S. Yang, J.G. Chung, Involvement of matrix metalloproteinases on the inhibition of cells invasion and migration by emodin in human neuroblastoma SH-SY5Y cells, Neurochem. Res. 34 (2009) 1575-1583.

[111] Y.M. Han, S.K. Lee, D.G. Jeong S.E. Ryu, D.C. Han, D.K. Kim, B.M. Kwon, Emodin inhibits migration and invasion of DLD-1 (PRL-3) cells via inhibition of PRL-3 phosphatase activity, Bioorg. Med. Chem. Lett. 22 (2012) 323-326.

[112] K.B. Singh, S.K. Trigun, Apoptosis of Dalton's lymphoma due to in vivo treatment with emodin is associated with modulations of hydrogen peroxide metabolizing antioxidant enzymes, Cell Biochem. Biophys. (2011).

[113] Y.C. Chang, T.Y. Lai, C.S. Yu, H.Y. Chen, J.S. Yang, F.S. Chueh, C.C. Lu, J.H. Chiang W.W. Huang, C.Y. Ma, J.G. Chung, Emodin induces apoptotic death in murine myelomonocytic leukemia WEHI-3 cells in vitro and enhances phagocytosis in leukemia mice in vivo, Evid. Based Compl. Alternat. Med. 2011 (2011) 523596.

[114] W. Chun-Guang, Y. Jun-Qing, L. Bei-Zhong, J. Dan-Ting, W. Chong, Z. Liang, Z. Dan, W. Yan, Anti-tumor activity of emodin against human chronic myelocytic leukemia K562 cell lines in vitro and in vivo, Eur. J. Pharmacol. 627 (2010) 33-41.
[115] L. Zhang, Y.K. Lau, W. Xia, G.N. Hortobagyi, M.C. Hung, Tyrosine kinase inhibitor emodin suppresses growth of HER-2/neu-overexpressing breast cancer cells in athymic mice and sensitizes these cells to the inhibitory effect of paclitaxel, Clin. Cancer Res. 5 (1999) 343-353.

[116] K.A. Manu, M.K. Shanmugam, T.H. Ong, A Subramaniam, K.S. Siveen, E. Perumal, R.P. Samy, P. Bist, L.H. Lim, A.P. Kumar, K.M. Hui, G. Sethi, Emodin suppresses migration and invasion through the modulation of CXCR4 expression in an orthotopic model of human hepatocellular carcinoma, PLoS ONE 8 (2013) e57015.

[117] Q. Guo, Y. Chen, B. Zhang, M. Kang, Q. Xie, Y. Wu, Potentiation of the effect of gemcitabine by emodin in pancreatic cancer is associated with survivin inhibition, Biochem. Pharmacol. 77 (2009) 1674-1683.

[118] J. Koyama, I. Morita, K. Tagahara, Y. Nobukuni, T. Mukainaka, M. Kuchide, H. Tokuda, H. Nishino, Chemopreventive effects of emodin and cassiamin B in mouse skin carcinogenesis, Cancer Lett. 182 (2002) 135-139.

[119] W.T. Wei, H. Chen, Z.L. Ni, H.B. Liu, H.F. Tong, L. Fan, A. Liu, M.X. Qiu, D.L. Liu, H.C. Guo, Z.H. Wang, S.Z. Lin, Antitumor and apoptosis-promoting properties of emodin, an anthraquinone derivative from Rheum officinale Baill, against pancreatic cancer in mice via inhibition of Akt activation, Int. J. Oncol. 39 (2011) 1381-1390. 